\title{
ANALISIS PERBEDAAN PROFITABILITAS SEBELUM DAN SESUDAH MEMENANGKAN TOP CSR (CORPORATE SOCIAL RESPONSIBILITY)
}

\author{
Sixtia Apriyana Asrul, Wiwik Andriani, Eka Rosalina \\ Jurusan Akuntansi, Politeknik Negeri Padang \\ Email: Sixtiaapriyanaa@yahoo.co.id \\ Jurusan Akuntansi, Politeknik Negeri Padang \\ Email:wi_andriani@yahoo.com \\ Jurusan Akuntansi, Politeknik Negeri Padang \\ Email: ekarosalinapnp@yahoo.com
}

\begin{abstract}
This study aimed to examine whether there are differences in the profitability of a company before and after winning TOP CSR. The data used in this study is secondary data obtained from the financial statements of companies listed on the Indonesia Stock Exchange for the period 2008-2017. The sample of this study consisted of 17 companies using purposive sampling, ie companies that won TOP CSR from 2011-2017, companies listed on the Indonesia Stock Exchange and companies that had issued 3 years of financial statements after winning the CSR TOP. The variable used in this study is profitability which is proxied by Return On Assets (ROA), Return On Equity (ROE) and Net Profit Margin (NPM). Hypothesis testing is carried out by Paired Sample T-test using the IBM SPSS Version 20 software. Based on the tests carried out, it can be concluded that there are differences in profitability as seen from the ROA side, whereas when viewed from the ROE and NPM side it is not there are differences in profitability.
\end{abstract}

Keywords: TOP CSR, ROA, ROE and NPM

\section{ABSTRAK}

Penelitian ini bertujuan untuk menguji apakah terdapat perbedaan profitabilitas perusahaan sebelum dan sesudah memenangkan TOP CSR. Data yang digunakan dalam penelitian ini adalah data sekunder yang diperoleh dari laporan keuangan perusahaan yang terdaftar di Bursa Efek Indonesia periode 20082017. Sampel penelitian ini terdiri dari 17 (tujuh belas) perusahaan dengan menggunakan Purposive Sampling, yaitu perusahaan yang menang TOP CSR dari tahun 2011-2017, perusahaan yang terdaftar di Bursa Efek Indonesia dan perusahaan yang telah menerbitkan 3 tahun laporan keuangan setelah menang TOP CSR . Variabel yang digunakan dalam penelitian ini adalah profitabilitas yang diproksikan dengan Return On Asset (ROA), Return On Equity (ROE) dan Net Profit Margin (NPM). Pengujian hipotesis dilakukan dengan Uji Beda t-test (Paired Sample T-test) dengan menggunankan software IBM SPSS Versi 20. Berdasarkan pengujian yang dilakukan, dapat disimpulkan bahwa terdapat perbedaan profitabilitas yang dilihat dari sisi ROA, sedangkan jika dilihat dari sisi ROE dan NPM tidak terdapat perbedaan profitabilitas.

Kata kunci: TOP CSR, ROA, ROE dan NPM 


\section{PENDAHULUAN}

Dalam sebuah perusahaan atau badan usaha, kegiatan bisnis menjadi perilaku utama dari para pelaku bisnis. Perusahaan selama ini dianggap sebagai sebuah lembaga yang memberikan keuntungan bagi masyarakat dan perusahaan tersebut, dimana menurut pendekatan akuntansi tradisional, perusahaan harus bisa memaksimalkan labanya agar dapat memberikan sumbangan yang maksimum kepada masyarakat (Henny dan Murtanto, 2001). Namun, kegiatan bisnis ini tetap berorientasi pada keuntungan tanpa dibatasi oleh perbedaan sistem hukum yang ada. Kegiatan bisnis tersebut terutama yang bergerak di bidang pemanfaatan sumber daya alam baik secara langsung maupun yang tidak langsung tentunya memberikan dampak pada lingkungan sekitarnya seperti masalah-masalah polusi, limbah, keamanan produk dan tenaga kerja.

Dewasa ini kesadaran akan lingkungan sudah meningkat. Masalah pencemaran yang terjadi di Indonesia sudah banyak menarik perhatian, mulai lapisan bawah sampai lapisan atas. Kemudian setiap pemerintah daerah mewajibkan pembuatan instalasi pengolahan limbah kepada pimpinan industri di daerahnya. Bahkan sudah ada yang diajukan ke pengadilan karena pelanggaran terhadap limbah. Perusahaan-perusahaan baru pun banyak yang tumbuh dan berkembang di sekitar masyarakat, dan tidak sedikit pula yang merugikan masyarakat sekitar karena limbah yang dihasilkan tidak diolah atau dibuang sebagaimana mestinya. Pembangunan yang dilakukan besar-besaran di Indonesia dapat meningkatkan kemakmuran bagi masyarakat namun disisi lain hal ini juga dapat membawa dampak negatif terhadap lingkungan hidup masyarakat tersebut. Dampak yang diakibatkan dari pencemaran lingkungan yang di sinyalir dari buangan proses industri dari perusahaan manufaktur yang mengakibatkan rusaknya ekosistem serta mengakibatkan sejumlah penyakit di masyarakat sekitar (Hadi, 2014).

Dalam meminimalisir dampak yang ditimbulkan, perusahaan harus bertanggungjawab terhadap lingkungan dan masyarakat sekitar atau disebut CSR (Corporate Social Responsibility). Corporate Social Responsibility (CSR) adalah operasi bisnis yang berkomitmen tidak hanya meningkatkan keuntungan perusahaan secara finansial, tetapi untuk meningkatkan sosial ekonomi kawasan holistik, melembaga, dan berkelanjutan (Ardianto dan Machfudz, 2011) menyatakan bahwa CSR merupakan kewajiban sosial bagi korporasi atas dampak dari keputusan yang dilakukan perusahaan terhadap masyarakat dan lingkungannya. Saat ini banyak perusahaan yang menerapkan program CSR terkait dengan aturan yang ada, karena CSR merefleksikan nilai perusahaan yang berpijak pada 3 (tiga) aspek yaitu aspek ekonomi, aspek sosial, dan aspek lingkungan untuk menjamin keberlanjutan perusahaan.

Konsep CSR pada umumnya menyatakan bahwa tanggung jawab perusahaan tidak hanya terhadap pemiliknya atau pemegang saham saja tetapi juga terhadap para stakeholder yang terkait dan/atau terkena dampak dari keberadaan perusahaan. Perusahaan yang menerapkan dan menjalankan aktivitas CSR akan memperhatikan dampak operasional perusahaan terhadap kondisi sosial dan lingkungan dan berupaya agar dampaknya positif. Sehingga dengan adanya konsep CSR diharapkan kerusakan lingkungan yang terjadi di dunia, mulai dari penggundulan hutan, polusi udara dan air, hingga perubahan iklim dapat dikurangi (Apriliawati dan Wiwit, 2016).

Kebanyakan praktik CSR di Indonesia masih menggunakan paradigma lama lantaran manajemen perusahaan menganggap bahwa kegiatan CSR sekedar donasi 
kepada masyarakat dan tidak bermanfaat langsung ke perusahaan. Sudut pandang seperti ini seharusnya diubah oleh manajemen perusahaan. Kemudian, praktik CSR masih dalam batas Community Involvement and Development (CID) untuk memperoleh dukungan komunitas sekitar. Selain itu, program CSR terlalu beragam, kurang fokus, tidak terkait bisnis inti, dan belum menjadi bagian strategi bisnis.

Kemudian untuk meminimalisir keberagaman program CSR maka diadakanlah sebuah event bagi perusahaan yang mengungkapkan CSR dengan nama "Top CSR". TOP CSR adalah kegiatan penilaian dan pemberian penghargaan tertinggi kepada perusahaan-perusahaan yang beroperasional di Indonesia, yang dinilai telah menjalankan program CSR/ PKBL/Community Development terbaik. Penilaian CSR didasarkan pada keterkaitan CSR terhadap tiga hal yakni ISO 26000, strategi bisnis, dan praktik Good Corporate Governance (Tribunnews.com).

Di Indonesia sendiri, penelitian terkait CSR Award/TOP CSR belum ada ditemukan namun penelitian mengenai pengungkapan CSR dan mengikuti ISRA (Indonesia Sustainability Reporting Awards) telah banyak dilakukan. Penelitianpenelitian yang ada menunjukkan bahwa pengungkapan CSR berpengaruh terhadap kinerja keuangan yang diproksikan dengan profitabilitas. Kinerja perusahaan sendiri penting bagi berbagai pihak terutama bagi investor yang telah berinvestasi dalam perusahaan.

Penelitian terkait dengan pengungkapan CSR adalah penelitian Yustina Herry (2012) dengan judul analisis perbedaan tingkat profitabilitas sebelum dan sesudah pengungkapan CSR mendapatkan hasil bahwa tidak terdapat perbedaan profitabilitas sebelum dan sesudah pengungkapan CSR. Kemudian penelitian Febrianto Dwi Handoyo (2014) mengungkapkan bahwa adanya perbedaan profitabilitas setelah penerapan CSR. Kemudian penelitian Megi Oktriani Herman (2016) yang mengungkapkan bahwa tidak terdapat perbedaan kinerja keuangan perusahaan sebelum dan sesudah berpartisipasi dalam ISRA.

Di Indonesia sendiri, penelitian yang dilakukan masih banyak berkisar pada pengungkpan CSR dan kinerja keuangan peraih ISRA. Sementara penelitian mengenai peraih penghargaan CSR award/TOP CSR belum ada yang melakukan penelitian tersebut. Oleh karena itu, peneliti tertarik dengan penelitian pengungkapan CSR dengan judul "Analisis perbedaan tingkat profitabilitas sebelum dan sesudah memenangkan TOP CSR (Corporate Social Responbility)". Adanya hasil penelitian yang berbeda-beda, maka dalam penelitian ini peneliti tertarik dan ingin membuktikan perbedaan profitabilitas dengan diproksikan Return On Asset, Return On Equity dan Net Profit Margin terhadap perusahaan yang menang TOP CSR pada tahun 20112017.

\section{TINJAUAN PUSTAKA}

\section{CSR (Corporate Social Responsibility)}

Corporate Social Responsibility sebagai bentuk perhatian dari organisasi bisnis yang mulai memperhitungkan aspek lain di luar proses internal organisasi atau manajemen organisasi maupun masyarakat mulai berkembang konsep-konsep yang menuntut peran organisasi bisnis. Petkoski dan Twose (2003) mendefinisikan CSR sebagai komitmen bisnis yang berperan untuk mendukung pembangunan ekonomi, bekerjasama dengan karyawan dam keluarganya, masyarakat lokal dan masyarakat luas, untuk meningkatkan mutu hidup mereka dengan melakukan berbagai cara yang menguntungkan bagi bisnis dan pembangunan. Banyak perusahaan yang 
memanfaatkan kekayaan sumber daya alam dalam kegiatan operasinya, namun tidak peduli terhadap keadaan lingkungan dan masyarakat sekitarnya. Oleh sebab itu pemerintah mengeluarkan Undang-Undang No. 40 tahun 2007 tentang Perseroan Terbatas. Dalam pasal 74 UU tersebut mewajibkan perseroan yang bidang usahanya di bidang atau terkait dengan sumber daya alam untuk melaksanakan tanggung jawab sosial. Penelitian Iryani (2009) mengatakan bahwa triple bottom lines merupakan suatu konsekuensi dari definisi sustainable development yang mana mempunyai tiga elemen penting yaitu pertumbuhan ekonomi, perlindungan lingkungan dan kesejahteraan sosial

\section{TOP CSR}

TOP CSR adalah kegiatan penilaian dan pemberian penghargaan (award) tertinggi kepada perusahaan-perusahaan yang beroperasi di Indonesia, yang dinilai telah menjalankan program CSR/PKBL/Community Development terbaik. Penilaian CSR didasarkan pada keterkaitan CSR terhadap 3 hal yakni 1) ISO 26000, 2) Strategi Bisnis, dan 3) Praktik GCG. Kegiatan TOP CSR diselenggarakan oleh Majalah Businessnews Indonesia, yang bekerja sama dengan sejumlah lembaga kredibel seperti Komite Nasional Kebijakan Governance/KNKG, Masyarakat CSR Indonesia, SGL Management, Asia Business Research Center, Mitra Bhadra Consulting, Yayasan PAKEM, PPM Manajemen, Alvara, Indonesia CSR Society, Dwika Consulting, Sinergi Daya Prima, dan SBC Sinergi Internasional (inilah.com). Kegiatan TOP CSR ini tergolong Award CSR paling kredibel di Indonesia. Selain mendapatkan nilai tambah dalam presentasi dan wawancara penjurian, setiap peserta juga mendapatkan feedback tertulis untuk pengembangan CSR perusahaan di masa mendatang sehingga tak heran jika kegiatan TOP CSR ini diiikuti oleh banyak perusahaan (inilah.com ).

\section{Profitabilitas}

Profitabilitas adalah kemampuan perusahaan melaksanakan kegiatan operasionalnya untuk memperoleh laba dalam hubungannya dengan penjualan, total aktiva maupun modal sendiri (Niki, 2006). Profitabilitas merupakan sebuah faktor yang seharusnya mendapat perhatian penting bagi perusahaan karena untuk dapat melangsungkan hidupnya, suatu perusahaan harus berada dalam keadaan yang menguntungkan (profitable). Tanpa adanya keuntungan (profit) maka akan sulit bagi perusahaan untuk mendapatkan modal dari luar. Dalam melakukan analisis pada perusahaan, di samping melihat laporan keuangan perusahaan juga bisa dilakukan dengan menggunakan analisis rasio keuangan.

Profitabilitas suatu perusahaan dapat dihitung dan diukur dengan menghubungkan antara keuntungan atau laba yang diperoleh dari kegiatan pokok perusahaan dengan kekayaan atau asset yang dimiliki untuk menghasilkan keuntungan perusahaan (operating asset). Menghitung rasio profitabilitas dapat dilakukan dengan menggunakan perbandingan antara berbagai komponen yang ada di dalam laporan keuangan, terutama laporan keuangan neraca dan laporan laba rugi. Pengukuran dapat dilakukan untuk beberapa periode operasi. Tujuannya adalah agar terlihat perkembangan perusahaan dalam rentang waktu tertentu, baik penurunan ataupun kenaikan, sekaligus mencari penyebab perubahan tersebut (Herry dan Stefanus, 2012). Oleh karena itu, rasio profitabilitas ini sering disebut sebagai salah satu alat ukur kinerja keuangan manajemen. Jenis-jenis rasio profitabilitas yang 
sering dipakai untuk meninjau kemampuan perusahaan dalam menghasilkan laba, yaitu :

\section{Net Profit Margin (NPM)}

Rasio ini memberi gambaran laba untuk para pemegang saham sebagai persentase dari penjualan dan ukuran kemampuan perusahaan untuk mengubah setiap rupiah yang diperoleh dari penjualan menjadi keuntungan bersih (net profit) (Herman, 2016).

2. Return On Asset (ROA)

Rasio ini mengukur kemampuan perusahaan atas keseluruhan dana yang ditanamkan dalam aktifitas yang digunakan untuk aktifitas operasi perusahaan dengan tujuan menghasilkan laba dengan memanfaatkan aktiva yang dimilikinya (Herman, 2016).

3. Return On Equity (ROE)

Return on equity (ROE) adalah laba bersih perusahaan setelah dikurangi pajak dibagi dengan ekuitas pemilik. Rasio ini menunjukkan tingkat pengembalian ekuitas dari aktifitas investasi dan penjualan yang dilakukan (Herman, 2016).

4. Gross Profit Margin (GPM)

Rasio ini menggambarkan presentase laba kotor yang dihasilkan oleh setiap pendapatan perusahaan. Harapannya, makin tinggi GPM, maka akan makin baik (Herman, 2016).

5. Operating Margin (OM)

Operating margin mencerminkan kemampuan manajemen mengubah aktivitasnya menjadi laba. Harapannya, makin tinggi OM, maka akan makin baik (Herman, 2016).

\section{Perumusan Hipotesis}

Beberapa penelitian mengenai profitabilitas sudah pernah dilakukan sebelumya. Penelitian tersebut antara lain dilakukan oleh Yustina Herry dan Stefanus Ariyanto (2012) yang meneliti apakah ada perbedaan tingkat profitabilitas sebelum dan sesudah pengungkapan CSR pada perusahaan dalam industri pertambangan dan farmasi yang terdaftar di Bursa Efek Indonesia. Penelitian ini menyimpulkan bahwa tidak terjadinya perbedaan tingkat profitabilitas untuk satu tahun sebelum dengan satu tahun sesudah pengungkapan CSR. Hal ini di buktikan dengan uji Paired Sample $T$-Test yang menunjukkan tidak terdapat perbedaan profitabilitas (ROA, ROE, NPM) antara sebelum dan sesudah pengungkapan program CSR dikarenakan memiliki nilai sig yang lebih besar dari nilai probabilitasnya yaitu 0,05.

Febrianto Dwi Handoyono (2014) dalam penelitiannya pengaruh sebelum dan setelah penerapan tanggung jawab sosial terhadap profitabilitas dengan objeknya adalah PT. Medco Energi International, Tbk. Hasil penelitiannya adalah terdapatnya perbedaan profitabilitas PT. Medco Energi International, Tbk sebelum dan setelah penerapan CSR. Hal ini dibuktikan Uji Paired Sample Statistics yang menunjukkan bahwa rata-rata profitabilitas PT. Medco Energi International, Tbk mengalami penurunan yang sebelumnya 0,0777107 (sebelum CSR) menjadi 0,0375642 (setelah CSR).

Dengan mengacu pada penelitian Febrianto Dwi Handoyono dan Nurul Chaeriyah Anwar (2015), maka peneliti menyusun hipotesis dengan menggunakan rasio profitabilitas yang sama dengan penelitian Febrianto Dwi Handoyono (2014) dan Nurul Chaeriyah Anwar (2015). Hipotesis dalam penelitian ini adalah : 
$\mathrm{H}_{1}=$ Adanya perbedaan ROA (Return On Assets) sebelum dan sesudah menang dalam TOP CSR

$\mathrm{H}_{2}=$ Adanya perbedaan ROE (Return On Equity) sebelum dan sesudah menang dalam TOP CSR

$\mathrm{H}_{3}=$ Adanya perbedaan NPM (Net Profit Margin) sebelum dan sesudah menang dalam TOP CSR

\section{METODE PENELITIAN Jenis Penelitian}

Jenis penelitian ini adalah penelitian kuantitatif dengan pengolahan datanya menggunakan aplikasi SPSS. Data yang digunakan dalam penelitian ini adalah data sekunder. Data tersebut dapat di peroleh dari website perusahaan-perusahaan yang memenangkan TOP CSR pada 2011-2017.

\section{Populasi dan Sampel Penelitian \\ Populasi Penelitian}

Populasi dari penelitian ini adalah perusahaan yang memenangkan TOP CSR dari tahun 2011-2017 sebanyak 93 (sembilan puluh tiga) perusahaan.

\section{Sampel Penelitian}

Pemilihan sampel dilakukan dengan menggunakan metode purposive sampling dengan tujuan untuk mendapatkan sampel yang representatif sesuai dengan kriteria yang ditentukan. Adapun kriteria dari sampel yang akan digunakan yaitu:

1. Perusahaan yang terdaftar di Bursa Efek Indonesia

2. Perusahaan yang menerbitkan laporan tahunan dari tahun 2008-2017

3. Perusahaan yang menjadi pemenang TOP CSR dan telah menerbitkan laporan tahunan 3 tahun setelah menang TOP CSR

4. Perusahaan yang menyajikan data terkait variabel penelitian.

\section{Teknik Pengumpulan Data}

Teknik pengumpulan data yang digunakan dalam penelitian ini adalah dokumentasi data sekunder berupa laporan keuangan, laporan tahunan ataupun laporan berkelanjutan perusahaan (sustainability report) yang telah dikeluarkan perusahaanperusahaan yang memenangkan TOP CSR. Laporan keuangan, laporan tahunan maupun laporan berkelanjutan tahun buku 2008 sampai dengan 2017 digunakan untuk menghitung rasio profitabilitas.

Data tersebut diperoleh melalui website yang dimiliki oleh Bursa Efek Indonesia (BEI) yaitu www.idx.co.id. Studi pustaka atau literatur melalui buku teks, jurnal ilmiah, artikel dan sumber tertulis lainnya yang berkaitan dengan informasi yang dibutuhkan juga dijadikan sumber pengumpulan data.

\section{Variabel Penelitian}

Variabel yang diukur dalam penelitian ini adalah variabel yang memberi gambaran tentang profitabilitas perusahaan. Penilaian profitabilitas perusahaan dapat dilakukan dengan membuat analisis terhadap laporan keuangan perusahaan yang bersangkutan. Analisis laporan keuangan dapat dilakukan dengan menggunakan 
ukuran tertentu yaitu dengan rasio profitabilitas. Dalam penelitian ini rasio profitabilitasnya yaitu :

1. Net Profit Margin (NPM)

$$
\mathrm{NPM}=\frac{\text { Profit After Tax }}{\text { Revenue }}
$$

2. Return On Asset (ROA)

$$
\mathrm{ROA}=\frac{\text { Laba Bersih }}{\text { Total Aktiva }}
$$

3. Return On Equity (ROE)

$$
\mathrm{ROE}=\frac{\text { Profit After Tax }}{\text { Net } \text { Worth }}
$$

\section{Metode Analisis Data}

Metode analisis data yang digunakan dalam penelitian ini adalah :

\section{Statistik Deskriptif}

Dalam penelitian ini akan dilakukan dengan pendekatan kuantitatif dengan alat statistik deskriptif dan pengujian hipotesis. Statistik deskriptif ini digunakan untuk memberikan deskripsi mengenai variabel-variabel yang akan diteliti yaitu Profitability Ratio ( Return on Asset, Return on Equity, dan Net Profit Margin ). Hasil analisis deskriptif meliputi nilai rata-rata, nilai minimum, nilai maximum dan standar deviasi yang berguna untuk mendukung hasil interpretasi teknik lain. (Herman, 2016).

Peneliti menggunakan data perubahan rasio dari tahun 2008-2017 (sebelum dan sesudah memenangkan TOP CSR). Selanjutnya pengujian hipotesis penelitian dengan uji t.

\section{Uji t (Paired Sample t-test)}

Indikator untuk Paired Sample t test menurut Ghozali (2006) ditentukan dengan :

1) Jika $\alpha=0,05$ lebih kecil atau sama dengan nilai sig. Atau ( $\alpha=0,05 \leq \operatorname{sig}$ ), yang artinya tidak terdapat perbedaan yang signifikan atau Ha ditolak, dan Ho diterima.

2) Jika $\alpha=0,05$ lebih besar atau sama dengan nilai sig. atau ( $\alpha=0,05 \geq \operatorname{sig}$ ), yang artinya terdapat perbedaan yang signifikan atau Ho ditolak dan Ha diterima.

Dari uji perbandingan statistik dengan menggunakan paired sample t-test maka akan diambil kesimpulan untuk menerima atau menolak Ho. Pengujian ini untuk membuktikan apakah sampel penelitian memiliki net profit margin, return on asset, dan return on equity yang berbeda secara signifikan atau tidak ketika sebelum dan sesudah memenangkan TOP CSR.

\section{HASIL DAN PEMBAHASAN}

\section{Gambaran Sampel Penelitian}

Berdasarkan proses pemilihan sampel terdapat 93 (sembilan puluh tiga) perusahaan yang memenangkan TOP CSR dari tahun 2011-2017. Namun terdapat 26 perusahaan 
yang belum ada laporan tahunan/laporan keuangan 3 (tiga) tahun setelah menang dan di antara 93(sembilan puluh tiga) perusahaan tersebut ada 50 (lima puluh) perusahaan yang tidak ada di Bursa Efek Indonesia. Akhirnya hasil pengumpulan sampel ini didapat 17(tujuh belas) perusahaan yang bisa dijadikan sampel.

Tujuh belas perusahaan yang dijadikan sampel ini terdiri dari berbagai sektor. Dimana 17 (tujuh belas) perusahaan ini adalah perusahaan yang terdaftar di Bursa Efek Indonesia. Alasan peneliti memilih perusahaan yang terdaftar di Bursa Efek Indonesia adalah agar peneliti bisa mendapatkan data dari variabel-variabel yang peneliti gunakan dalam penelitian ini.

Tabel 1

Nama Perusahaan dan Tahun Menang TOP CSR

\begin{tabular}{|c|l|c|}
\hline No & \multicolumn{1}{|c|}{ Nama Perusahaan } & $\begin{array}{c}\text { Tahun menang TOP } \\
\text { CSR }\end{array}$ \\
\hline 1 & PT Astra International Tbk & 2013 \\
\hline 2 & PT Holcim Indonesia Tbk & 2013 \\
\hline 3 & PT Bank Mandiri & 2014 \\
\hline 4 & PT Bank Rakyat Indonesia & 2015 \\
\hline 5 & PT Adaro Energy & 2014 \\
\hline 6 & PT HM Sampoerna & 2014 \\
\hline 7 & PT Vale Indonesia & 2014 \\
\hline 8 & PT Bumi Resources & 2014 \\
\hline 9 & Bank Panin Indonesia & 2012 \\
\hline 10 & PT Telekomunikasi Indonesia & 2011 \\
\hline 11 & PT Aneka Tambang & 2011 \\
\hline 12 & Bank Negara Indonesia & 2011 \\
\hline 13 & PT Smart & 2011 \\
\hline 14 & PT Indocement Tunggal Prakarsa & 2011 \\
\hline 15 & PT Astra Agro Lestari & \\
\hline 16 & PT Bukit Asam & \\
\hline 17 & PT Bakrieland Development & \\
\hline
\end{tabular}

Sumber : Data sekunder, 2018

\section{Hasil penelitian} Statistik Deskriptif 
Hasil Analisis Statistik Deskriptif

\begin{tabular}{|l|r|r|r|r|r|}
\hline & \multicolumn{1}{|c|}{ N } & \multicolumn{1}{c|}{ Minimum } & \multicolumn{1}{c|}{ Maximum } & \multicolumn{1}{c|}{ Mean } & Std. Deviation \\
\hline ROA_SEBELUM & 51 &,- 096 &, 590 &, 14084 &, 159776 \\
ROA_SESUDAH & 51 &,- 644 &, 303 &, 06316 &, 132441 \\
ROE_SEBELUM & 51 & $-1,799$ & 2,318 &, 29375 &, 527767 \\
ROE_SESUDAH & 51 &,- 122 &, 848 &, 27224 &, 287289 \\
NPM_SEBELUM & 51 &,- 187 & 1,279 &, 20425 &, 201260 \\
NPM_SESUDAH & 51 & $-53,954$ & 13,978 &,- 55214 & 7,898172 \\
Valid N (listwise) & 51 & & & & \\
Sumber : Data Diolah, 2018 & & & & & \\
\hline
\end{tabular}

Pada Tabel 2 (dua) menggambarkan statistik deskriptif dari ROA, ROE dan NPM perusahaan sebelum dan sesudah memenangkan TOP CSR. Berdasarkan Tabel 2 (dua) ROA perusahaan sebelum memenangkan TOP CSR memiliki nilai terendah yakni -0,096 dari PT Bumi Resources Tbk tahun 2012 dan setelah memenangkan TOP CSR ROA perusahaan memiliki nilai terendah -0,644 dari PT Bumi Resources Tbk tahun 2015.

Kemudian nilai tertinggi ROA perusahaan sebelum menang TOP CSR sebesar 0,590 dari PT Telekomunikasi Indonesia Tbk tahun 2009 dan setelah menang memiliki nilai ROA tertinggi 0,303 dari PT HM Sampoerna Tbk tahun 2015. Selanjutnya nilai rata-rata ROA perusahaan sebelum memenangkan TOP CSR yakni 0,140 dan setelah menang memiliki nilai rata-rata ROA perusahaan yakni 0,063.

Bila dilihat dari standar deviasinya, ROA perusahaan sebelum dan sesudah memenangkan TOP CSR mengalami penurunan. Nilai standar deviasi ROA perusahaan yang sebelum menang yakni 0,16 dan setelah menang menjadi 0,13 sehingga dapat dikatakan bahwa ROA yang dihasilkan oleh perusahaan sesudah memenangkan TOP CSR mengalami penurunan dari tingkat efesiensi asset yang ada di perusahaan dalam menghasilkan laba operasi.

ROE perusahaan sebelum memenangkan TOP CSR memiliki nilai terendah yakni -1,799 dari PT Bumi Resources Tbk tahun 2012 dan setelah memenangkan TOP CSR, ROE perusahaan memiliki nilai terendah -0,122 dari PT Bakrieland Development tahun 2012. Kemudian nilai tertinggi ROE perusahaan sebelum menang TOP CSR yakni 2,318 dari PT Astra Agro Lestari tahun 2010 dan setelah menang memiliki nilai tertinggi 0,848 dari PT Bumi Resources tahun 2017. Selanjutnya nilai rata-rata ROE perusahaan sebelum memenangkan TOP CSR yakni 0,294 dan setelah menang memiliki nilai rata-rata ROE perusahaan yakni 0,272.

Bila dilihat dari standar deviasinya, ROE perusahaan sebelum dan sesudah memenangkan TOP CSR mengalami penurunan. Nilai standar deviasi ROE perusahaan yang sebelum menang yakni 0,527 dan setelah menang menjadi 0,287 sehingga dapat dikatakan bahwa ROE yang dihasilkan oleh perusahaan sesudah memenangkan TOP CSR mengalami penurunan dari tingkat efesiensi ekuitas yang ada di perusahaan dalam menghasilkan laba operasi.

NPM perusahaan sebelum memenangkan TOP CSR memiliki nilai terendah yakni -0,187 dari PT Bumi Resources Tbk tahun 2012 dan setelah memenangkan TOP CSR, NPM perusahaan memiliki nilai terendah -53,954 dari PT Bumi Resources Tbk 
tahun 2015. Kemudian nilai tertinggi NPM perusahaan sebelum menang TOP CSR yakni 1,279 dari Bank Negara Indonesia tahun 2009 dan setelah menang memiliki nilai tertinggi 13,978 dari PT Bumi Resources tahun 2017. Selanjutnya nilai rata-rata NPM perusahaan sebelum memenangkan TOP CSR yakni 0,204 dan setelah menang memiliki nilai rata-rata ROE perusahaan yakni -0,552.

Bila dilihat dari standar deviasinya, NPM perusahaan sebelum dan sesudah memenangkan TOP CSR mengalami peningkatan. Nilai standar deviasi NPM perusahaan yang sebelum menang yakni 0,201 dan setelah menang menjadi 7,898 sehingga dapat dikatakan bahwa NPM yang dihasilkan oleh perusahaan sesudah memenangkan TOP CSR mengalami peningkatan dari tingkat efesiensi penjualan/pendapatan yang ada di perusahaan dalam menghasilkan laba operasi. Harapannya, semakin tinggi NPM maka akan semakin baik profitabilitas perusahaan.

\section{Analisis Data dan Pembuktian Hipotesis Pengujian $\mathrm{H}_{1}$}

Tabel 3

Hasil Uji Beda t Return On Asset Sebelum dan Sesudah memenangkan TOP CSR

Paired Samples Test

\begin{tabular}{|c|c|c|c|c|c|c|c|c|c|}
\hline & & \multicolumn{5}{|c|}{ Paired Differences } & \multirow[t]{3}{*}{$\mathrm{T}$} & \multirow[t]{3}{*}{$\overline{d f}$} & \multirow{3}{*}{$\begin{array}{l}\text { Sig. (2- } \\
\text { tailed) }\end{array}$} \\
\hline & & \multirow[t]{2}{*}{ Mean } & \multirow[t]{2}{*}{$\begin{array}{c}\text { Std. } \\
\text { Deviation }\end{array}$} & \multirow[t]{2}{*}{$\begin{array}{l}\text { Std. Error } \\
\text { Mean }\end{array}$} & \multicolumn{2}{|c|}{$\begin{array}{l}95 \% \text { Confidence } \\
\text { Interval of the } \\
\text { Difference }\end{array}$} & & & \\
\hline & & & & & Lower & Upper & & & \\
\hline ROA & $\begin{array}{l}\text { SEBELUM - } \\
\text { SESUDAH }\end{array}$ & ,07768 & , 145266 & ,02034 & ,036830 & ,11854 & 3,819 & 50 &, 000 \\
\hline
\end{tabular}

Sumber : Data Sekunder Diolah, 2018

Berdasarkan Tabel 3 (tiga) yang merupakan hasil uji beda t ROA perusahaan sebelum dan sesudah memenangkan TOP CSR yang diolah menggunakan SPSS Versi 20(dua puluh) di dapatkan hasil bahwa nilai sig. untuk variabel ROA sebesar 0,000. Ini berarti bahwa nilai sig. lebih kecil dari 0,05 yang berarti $\mathrm{H}_{\mathrm{o}}$ ditolak dan $\mathrm{H}_{1}$ diterima sehingga dapat dikatakan bahwa ada perbedaan yang signifikan antara perusahaan sebelum dan sesudah memenangkan TOP CSR yang di lihat dari ROA perusahaan. Hasil uji ini diperkuat oleh hasil penelitian Febrianto Dwi Handoyo (2014) yang menyatakan bahwa ada perbedaan profitabilitas yang dilihat dari sisi ROA pada perusahaan antara sebelum dan sesudah penerapan CSR.

\section{Pengujian $\mathrm{H}_{2}$}

Tabel 4

Hasil Uji Beda t Return On Equity Sebelum dan Sesudah Memenangkan TOP CSR

Paired Samples Test

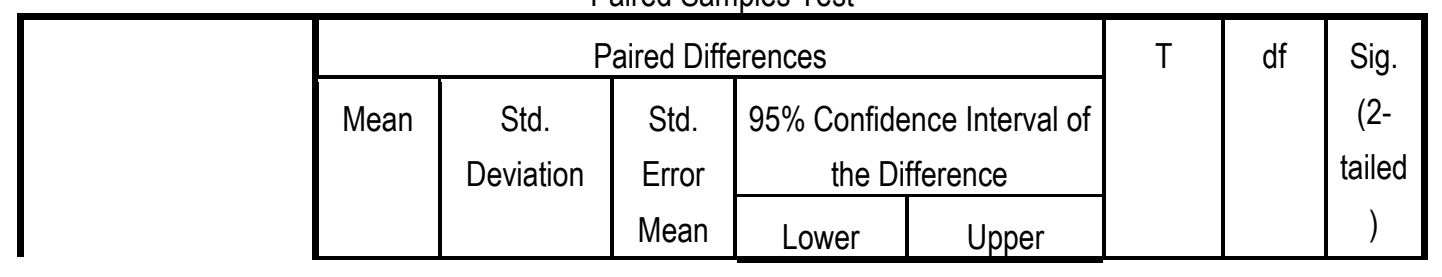




\begin{tabular}{|c|c|c|c|c|c|c|c|c|c|}
\hline & $\begin{array}{l}\text { SEBELUM } \\
\text { SESUDAH }\end{array}$ & ,0215 & ,4794 & ,0671 & -1133 & 1563 & ,320 & 50 & ,750 \\
\hline
\end{tabular}

Sumber : Data Sekunder Diolah, 2018

Pada Tabel 4 (empat) dapat dilihat hasil Uji Beda T ROE perusahaan sebelum dan sesudah memenangkan TOP CSR. Hasil Uji Beda T ROE perusahaan menghasilkan nilai sig. sebesar 0,750 yang artinya nilai sig. $>0,05$. Maka dapat disimpulkan bahwa $\mathrm{H}_{2}$ ditolak dan $\mathrm{H}_{\mathrm{o}}$ diterima artinya tidak terdapat perbedaan signifikan ROE perusahaan sebelum dan sesudah memenangkan TOP CSR. Hasil uji ini diperkuat oleh hasil penelitian Megi Oktarina Herman (2016) yang menyatakan bahwa tidak ada perbedaan kinerja keuangan yang dilihat dari sisi ROE pada perusahaan antara sebelum dan sesudah berpartisipasi dalam ISRA.

\section{Pengujian $\mathrm{H}_{3}$}

Tabel 5

Hasil Uji Beda t Net Profit Margint Sebelum dan Sesudah memenangkan TOP CSR

Paired Samples Test

\begin{tabular}{|c|c|c|c|c|c|c|c|c|c|}
\hline & \multicolumn{5}{|c|}{ Paired Differences } & \multirow[t]{3}{*}{$\mathrm{T}$} & \multirow[t]{3}{*}{$\mathrm{df}$} & \multirow{3}{*}{$\begin{array}{l}\text { Sig. (2- } \\
\text { tailed) }\end{array}$} \\
\hline & & \multirow[t]{2}{*}{ Mean } & \multirow[t]{2}{*}{$\begin{array}{c}\text { Std. } \\
\text { Deviation }\end{array}$} & \multirow[t]{2}{*}{$\begin{array}{l}\text { Std. Error } \\
\text { Mean }\end{array}$} & \multicolumn{2}{|c|}{$\begin{array}{l}95 \% \text { Confidence } \\
\text { Interval of the } \\
\text { Difference }\end{array}$} & & & \\
\hline & & & & & Lower & Upper & & & \\
\hline NPM & $\begin{array}{l}\text { SEBELUM - } \\
\text { SESUDAH }\end{array}$ & ,7563 & 7,8976 & 1,105899 & $-1,4648$ & 2,977 & ,684 & 50 & ,497 \\
\hline
\end{tabular}

Sumber : Data Sekunder Diolah, 2018

Pada tabel 5 (lima) dapat dilihat hasil uji beda t (paired sample t test) yang dilakukan peneliti menggunakan SPSS Versi 20 sehubungan dengan rasio NPM sebelum dan sesudah memenangkan TOP CSR. Dari hasil uji beda di dapatkan hasil nilai sig. 0,497 yang berarti nilai signifikan lebih besar dari 0,05 $(0,497>0,05)$ sehingga dapat disimpulkan bahwa $\mathrm{H}_{3}$ ditolak dan $\mathrm{H}_{0}$ diterima yang maksudnya tidak terdapat perbedaan NPM perusahaan sebelum dan sesudah memenangkan TOP CSR.

Hasil uji ini diperkuat oleh hasil penelitian Megi Oktarina Herman (2016) yang menyatakan bahwa tidak ada perbedaan kinerja keuangan yang dilihat dari sisi NPM pada perusahaan antara sebelum dan sesudah berpartisipasi dalam ISRA.

\section{Pembahasan Analisis Data}

Tabel 6

Ringkasan hasil uji t untuk 3 tahun sebelum memenangkan TOP CSR dan 3 tahun sesudah memenangkan TOP CSR untuk seluruh sampel

\begin{tabular}{|c|c|c|c|}
\hline \multicolumn{2}{|l|}{} & Sig. (2 - tailed ) & $\mathrm{H}_{\mathrm{a}}$ \\
\hline ROA & Sebelum - Sesudah & 0,000 & Diterima \\
\hline
\end{tabular}




\begin{tabular}{|c|c|c|c|}
\hline ROE & Sebelum - Sesudah & 0,750 & Ditolak \\
\hline NPM & Sebelum - Sesudah & 0,497 & Ditolak \\
\hline
\end{tabular}

Sumber : Data Sekunder Diolah, 2018

Berdasarkan tabel 6 (enam) dijelaskan lebih lanjut bahwa hasil penelitian ini menunjukkan bahwa tidak ada perbedaan profitabilitas dari sisi ROE dan NPM antara sebelum dan sesudah memenangkan TOP CSR sehingga hipotesis ditolak. Hasil penelitian ini mendukung penelitian Yustina Herry dan Stefanus (2012) menyatakan bahwa tidak terdapat perbedaan profitabilitas dari sisi ROE dan NPM dalam industri pertambangan dan farmasi yang terdaftar di Bursa Efek Indonesia. Penelitian Megi Oktriani Herman (2016) menunjukkan bahwa tidak terdapat perbedaan kinerja keuangan yang dilihat dari ROA dan NPM yang signifikan sebelum dan sesudah berpartisipasi dalam ISRA. Penelitian Febrianto Dwi Handoyo (2014) yang menyatakan terdapat perbedaan profitabilitas dengan rasio ROA pada perusahaan PT. Medco Energi International Tbk antara 10 tahun sebelum melaksanakan CSR dan 10 tahun setelah melaksanakan CSR.

Penelitian ini tidak konsisten dengan hasil penelitian Nurul Chaeriyah Anwar (2015) yang menyatakan terdapat perbedaan profitabilitas yang dilihat dari sisi ROI/ROE dengan penurunan yang signifikan antara profitabilitas sebelum dan setelah penerapan CSR pada PT Angkasa Pura 1 Cabang Bandar Udara Sultan Hasanuddin Makassar sedangkan hasil penelitian ini menunjukkan tidak terdapat perbedaan ROE sebelum dan sesudah memenangkan TOP CSR.

Hasil penelitian ini menunjukkan bahwa wacana tentang TOP CSR masih belum direspon oleh masyarakat khususnya investor di Indonesia. Hal ini disebabkan karena masih ada point-point lain selain menjadi pemenang TOP CSR yang menjadi perhatian bagi perusahaan serta masih banyak perusahaan beranggapan bahwa CSR adalah beban. Maka dari itu dibutuhkan pemahaman bagi perusahaan mengenai CSR agar perusahaan membuat dan melaksanakan CSR sehingga perusahaan bisa mengikuti award CSR dan mendapatkan feedback untuk pengembangan CSR di masa mendatang.

\section{KESIMPULAN DAN SARAN Kesimpulan}

Berdasarkan hasil pengujian statistik dan analisis yang telah dijelaskan pada bab sebelumnya maka dapat ditarik kesimpulan sebagai jawaban atas rumusan masalah yang mempertanyakan apakah terdapat perbedaan profitabilitas perusahaan sebelum dan sesudah memenangkan TOP CSR yang mencakup 8(delapan) sampel perusahaan dengan menggunakan rasio profitabilitas yaitu Return On Asset (ROA), Return On Equity (ROE), dan Net Profit Margin (NPM) yang di uji dengan menggunkan uji beda t (paired sample t test), maka diperoleh kesimpulan penelitian ini adalah :

1. Pengujian yang dilakukan untuk hipotesis $\mathrm{H}_{1}, \mathrm{H}_{2}, \mathrm{H}_{3}$ dengan variabel profitabilitas yaitu ROA, ROE, dan NPM membuktikan bahwa tidak terdapat perbedaan profitabilitas yang signifikan pada perusahaan sebelum dan sesudah memenangkan TOP CSR jika dilihat dari sisi ROE dan NPM namun jika dilihat dari sisi ROA maka membuktikan bahwa ada perbedaaan profitabilitas sebelum dan sesudah memenangkan TOP CSR. 
2. Hasil penelitian ini menunjukkan bahwa pelaksanaan CSR belum di respon kuat oleh perusahaan-perusahaan yang ada di Indonesia. Hal ini disebabkan karena perusahaan masih berfikir bahwa CSR adalah beban, padahal CSR adalah tanggungjawab yang harus dilaksanakan oleh perusahaan demi keberlanjutan perusahaan untuk selanjutnya. Jika perusahaan telah mengungkapkan CSR, maka perusahaan bisa mengikuti award-award terkait Saran CSR yang feedbacknya berguna bagi perusahaan, masyarakat dan investor.

1. Bagi peneliti selanjutnya dapat melakukan penambahan variabel profitabilitas perusahaan selain dari variabel yang pernah diteliti sebelumnya.

2. Penelitian berikutnya dapat memperpanjang periode penelitian agar dapat di peroleh jumlah sampel yang lebih banyak dan hasil penelitian yang lebih baik secara statisitk

\section{DAFTAR REFERENSI}

[1] Apriliawati, F dan Wiwit H. 2016. Pengaruh Corporate Social Responbility (CSR) sebelum dan sesudah diberlakukannya UU No. 40 tahun 2007 tentang Perseroan Terbatas. Dipresentasikan pada Prosiding Seminar Nasionasl INDOCOMPAC, Jakarta

[2] Ardianto, Elvinaro dan Machfudz, Dindin. 2011. Efek Kedermawanan Pebisnis dan CSR. Jakarta : Elex Media Komputindo

[3] Awuy, Vinta P., Yosefa S., dan Indah P. 2016. Pengaruh pengungkapan corporate social responbility (csr) terhadap Earnings Response Coefficient (ERC): Studi empiris : pada perusahaan pertambangan yang terdaftar di bursa efek indonesia pada tahun 2010-2013. Jurnal akuntansi dan keuangan

[4] Alma, Buchari, Donni J. 2014. Manajemen Bisnis Syariah. Bandung : Alfabeta

[5] Baridwan, Zaki. 2000. Intermediate Accounting. Edisi Ketujuh. Yogyakarta: BPFE-UGM

[6] Boediono, Gideon. 2005. Kualitas Laba: Study pengaruh Corporate Governance dan dampak manajemen laba dengan menggunakan analisis jalur. Makalah disampaikan dalam simposium nasional akuntansi VIII Solo

[7] Estiasih, S. 2014. Pengaruh corporate social responbility dan good corporate governance pada nilai perusahaan:karakteristik perusahaan sebagai variabel pemoderasi. Disertasi. Sekolah Tinggi Ilmu Ekonomi Indonesia Surabaya

[8] Fitriana, U. 2008. Analisis perbedaan kinerja keuangan perusahaan sebelum dan sesudah pengumuman Indonesia Sustainability Reporting Award (ISRA). Surakarta : Universitas Sebelas Maret

[9] Fujinuma, Tsuguoki. 2001. "Enhancing Corporate Governance-IFAC's Initiatives and the Role of the Accountancy Profession". Makalah dipresentasikan pada 
Konvensi Nasional Akuntansi Indonesia, 2001. Prosiding Paradigma Baru Profesi Akuntan Memasuki Milenium Ketiga : Good Governance. Cetakan ke-1. Jakarta

[10] Ghozali, Imam. 2006. Aplikasi Analisis Multivariate dengan Program SPSS Edisi Empat. Semarang : Badan Penerbit Universitas Diponegoro

[11] Hadi, R. 2014. Penerapan corporate social responbility (csr) pt unilever indonesia dalam mengatasi pencemaran lingkungan dan kepedulian terhadap anakanak.Ditelusuri 21 Juni 2018.

[12] Handoyono, Febrianto D. 2014. Pengaruh sebelum dan setelah penerapan tanggung jawab sosial terhadap profitabilitas perusahaan (studi kasus PT Medco Energi International, Tbk).

[13] Harmoni A, Andriyani A. 2008. Pengungkapan Corporate Social Responbility (CSR) pada official website perusahaan studi pada PT. Unilever Indonesia Tbk. Proceeding, Seminar Ilmiah Nasional Komputer dan Sistem Intelijen (KOMMIT 2008). Depok : Auditorium Universitas Gunadarma

[14] Henny dan Murtanto. 2001. Analisis pengungkapan sosial pada laporan tahunan. Media Risset, Auditing dan informasi,1 (2), 21-48

[15] Herman, Megi 0. 2016. Analisis perbedaan kinerja keuangan perusahaan antara sebelum dan sesudah berpartisipasi dalam Indonesia Sustainability Reeporting Awards (ISRA). Padang : Politeknik Negeri Padang

[16] Herry, Y. dan Stefanus A. 2012. Analisis Perbedaan tingkat profitabilitassebelum dan sesudah pengungkapan CSR(corporate social responsibility) pada perusahaan dalam industri pertambangan dan farmasi yang terdaftar di bursa efek indonesia. Jakarta Barat: Accounting Department, Faculty of Economic and Communication, BINUS University

[17] IICG. 2006. Pedoman umum Good Corporate Governance di Indonesia. Jakarta : Komite Nasional Kebijakan Governance

[18] Iriantara Y. 2004. Community relations, konsep dan aplikasinya. Bandung : Simbiosa Rekatama Media

[19] Iryani E. 2009. Komitmen stakeholders perusahaan terhadap kinerja sosial dan kinerja keuangan. [tesis]. Semarang : Universitas Diponegoro

[20] Niki, L. 2006. Dasar-dasar Manajemen Keuangan. Padang : Universitas Andalas

[21] Nur, M. (2012). Analisis faktor-faktor yang mempengaruhi pengungkapan corprate social responbility di Indonesia : Studi empiris pada perusahaan berkategori high profile yang listing di Bursa Efek Indonesia. Skripsi. Universitas Negeri Yogyakarta

[22] Petkoski D, Twose N. 2003. Public policy for corporate social responbility. Jointly sponsored by the world bank institute, the private sector development vice presidency of the world bank, and the international finance corporation 
[23] Priyanka, Felyna. 2013. Pengaruh pengungkapan csr (corporate social responsibility) terhadap profitabilitas pada perusahaan high profile yang terdaftar di bei periode 2009-2011.

[24] Rahayu, wiwik, dkk. 2014. Pengaruh pengungkapan csr (corporate social responsibility) terhadap profitabilitas perusahaan (studi pada perusahaan sektor pertambangan periode 2012-2013 yang terdaftar di bursa efek indonesia.

[25] Sartono, R. Agus. 2010. Manajemen Keuangan. Yogyakarta: BPFE

[26] Schar, Edson Ro, dkk. 2012. Corporate Social Responbility to build strong Brazilian Bank brand. Vol.33 ISS 6 ms436-451

[27] Situmeang, Ilona V. 2016. Corporate social responbility dipandang dari perspektif komunikasi organisasi. Yogyakarta : Ekuilibria

[28] Sukada S, Jalal.2008. Selayang pandang CSR: Ringkasan membumikan Bisnis Berkelanjutan. Dalam Mulya Amri Wicaksono Sarosa. CSR untuk penguatan kohesi sosial. Jakarta : Indonesia Bisnis Link

[29] Utami, Anindyati S. 2011. Pengaruh Kinerja Keuangan terhadap nilai perusahaan dengan pengungkapan CSR dan GCG sebagai variabel pemoderasi. Jember : Universitas Jember

[30] Waryanto, 2010. Pengaruh Karakteristik Good Corporate Governance terhadap Pengungkapan Corporate Social Responsibility di Indonesia. Skripsi Program S1 Fakultas Ekonomi Universitas Diponegoro

[31] Wibisono Y. 2007. Membedah Konsep dan Aplikasi CSR (Corporate Social Responbility). Gresik : Fascho Publishing

[32] Wiyono, Gendro. 2011. Merancang Penelitian Bisnis dengan Alat Analisis SPSS \& SmartPLS. Yogyakarta : STIM YKPN

[33] Bank Mandiri. 2018. Profil Perusahaan. https://www.bankmandiri.co.id/profilperusahaan Ditelusuri 31 Agustus 2018.

[34] Bank Rayat Indonesia. 2018.https://id.wikipedia.org/wiki/Bank Rakyat Indonesia. Ditelusuri 31 Agustus 2018.

[35] Brimatama. 2018. http://britama.com/index.php/2012/11/sejarah-dan-profilsingkat-elty/. Ditelusuri 19 September 2018

[36] CSR INDONESIA. 2016. Inilah Daftar The Winner of Global CSR Award 2015. Ditelusuri 10 Juli 2018. http://csr-indonesia.com/2016/04/21/inilah-daftarthe-winner-of-global-csr-award-2015/

[37] Dina Amelia. 2017. Definisi dan Cara Menghitung ROI dengan Benar. Ditelusuri 18 Agustus 2018. https://www.jurnal.id/id/blog/2017/definisi-dan-caramenghitung-roi-dengan-benar 
[38] Duniaenergi. 2017. Pertamina Hulu Energi Juara TOP CSR 2017. Ditelusuri 13 Juli 2018 http://www.dunia-energi.com/pertamina-hulu-energi-juara-top-csr$\underline{2017 /}$

[39] HM Sampoerna. 2018. https://id.wikipedia.org/wiki/HM Sampoerna. Ditelusuri 31 Agustus 2018.

[40] Inilahcom. 2017. Inilah Sederet Emiten Raih TOP CSR. Ditelurusi 6 Juli 2018 http://pasarmodal.inilah.com/read/detail/2370856/inilah-sederet-emitenraih-top-csr-2017

[41] Merdeka.com. 2018. Biografi Holcim. https://www.merdeka.com/holcimindonesia/. Ditelusuri 31 Agustus 2018.

[42] Mobile Statstik. 2018. https://www.mobilestatistik.com/parametrik-nonparametrik/.Ditelusurui 19 September 2018

[43] Nurman, R. 2014. Penerapan Corporate Social Responbility (CSR) PT Unilever Indonesia dalam Mengatasi Pencemaran Lingkungan dan Kepedulian terhadap Anak-anak, Ditelusuri 21 Juni 2018 http://riandjavu.blogspot.com/2014/06/csr.html

[44] Panin Bank. 2013. http://www.panin.co.id/pages/413/mengapa-panin-bank. Ditelusuri 19 September 2018.

[45] PT Aneka Tambang Tbk. 2018. Ditelusuri 19 September 2018 http://www.antam.com/index.php?option=com content\&task=view\&id=32\&It emid=2\&lang=id

[46] PT Astra International Tbk. 2018. Tentang Astra. https://www.astra.co.id/About-Astra. Ditelusuri 31 Agustus 2018

[47] PT Bank Negara Indonesia (BNI). 2018. Ditelusuri 19 September 2018 http://www.bni.co.id/idid/perusahaan/tentangbni/sejarah.

[48] PT Bukit Asam. 2018. http://www.ptba.co.id/id/tentang/profil. Ditelusuri 19 September 2018

[49] PT Indocement Tunggal Prakarsa. 2018. Ditelusuri 19 September 2018 http://www.indocement.co.id/v5/id/company/indocement-in-brief/briefdescription

[50] PT Smart Tbk. 2018. Ditelusuri 19 September 2018. https://www.smarttbk.com/tentang/

[51] Sanjaya, Ade. 2015. Pengertian Profitabilitas Menurut Para Ahli. Ditelurusi 10 Juli $2018 \quad$ http://www.landasanteori.com/2015/10/pengertian-rasioprofitabilitas.html

[52] Telkomsel. 2013. https://jobtrenurtika.wordpress.com/sejarah-singkat-pttelekomunikasi-indonesia-tbk/. Ditelusuri 19 September 2018. 
[53] Tribunnews.com. 2012. PT Aneka Tambah Raih Juara Umum USRA 2012. Ditelusuri 10 Juli 2018 http://www.tribunnews.com/bisnis/2012/12/03/ptaneka-tambang-raih-juara-umum-isra-2012

[54] Undang-Undang Nomor 40 tahun 2007. Ditelusuri 19 September 2018. https://www.google.com/url?sa=t\&rct=j\&q=\&esrc=s\&source=web\&cd=1\&cad =rja\&uact=8\&ved=2ahUKEwiYk6b7t8jdAhXNXSsKHQm0C7cQFjAAegQIABAC\& url=http\%3A\%2F\%2Feodb.ekon.go.id\%2Fdownload\%2Fperaturan\%2Fundan gundang\%2FUU 40 2007.PDF\&usg=AOvVaw0 qBgIeEH4gsbPAAOMoZd9

[55] Vale. 2018. http://www.vale.com/indonesia/BH/aboutvale/Pages/default.aspx. Ditelusuri 31 Agustus 2018. 